\title{
Evaluation of Physical, Thermal and Spectroscopic Properties of Biofield Treated $p$-Hydroxyacetophenone
}

\author{
Mahendra Kumar Trivedi ${ }^{1}$, Alice Branton ${ }^{1}$, Dahryn Trivedi ${ }^{1}$, Gopal Nayak ${ }^{1}$, Ragini Singh ${ }^{2}$ and Snehasis Jana ${ }^{2 *}$ \\ ${ }^{1}$ Trivedi Global Inc., 10624 S Eastern Avenue Suite A-969, Henderson, NV 89052, USA \\ ${ }^{2}$ Trivedi Science Research Laboratory Pvt. Ltd., Hall-A, Chinar Mega Mall, Chinar Fortune City, Hoshangabad Rd., Bhopal, Madhya Pradesh, India
}

\begin{abstract}
$P$-Hydroxyacetophenone ( $p \mathrm{HAP})$ is an aromatic ketone derivative that is mainly used in the manufacturing of various pharmaceuticals, flavours, fragrances, etc. In the present study, the impact of Mr. Trivedi's biofield energy treatment was analysed on various properties of pHAP viz. crystallite size, surface area, melting temperature, thermal decomposition, and spectral properties. The $p$ HAP sample was divided into two parts; one was kept as control sample while another part was named as treated sample. The treated sample was given the biofield energy treatment and various parameters were analysed as compared to the control sample by X-ray diffraction (XRD), surface area analyser, thermogravimetric analysis (TGA), differential scanning calorimetry (DSC), ultravioletvisible (UV-VIS), and Fourier transform infrared (FT-IR) spectroscopy. The XRD studies showed the decrease in crystallite size of the treated sample $(61.25 \mathrm{~nm})$ as compared to the control $(84.18 \mathrm{~nm})$; however the intensity of peaks in diffractogram was increased in treated sample. Besides, the surface area of treated sample was decreased by $41.17 \%$ as compared to the control. The TGA analysis revealed that onset temperature as well as $T_{\max }$ (maximum thermal decomposition temperature) was increased in the treated sample. However, the latent heat of fusion $(\Delta \mathrm{H})$ was decreased from $124.56 \mathrm{~J} / \mathrm{g}$ (control) to $103.24 \mathrm{~J} / \mathrm{g}$ in the treated sample. The treated and control samples were also evaluated by UV-Vis and FT-IR spectroscopy and did not show any significant alteration in spectra of treated sample as compared to the respective control. Hence, the overall results suggest that there was an impact of biofield energy treatment on the physical and thermal properties of $p$ HAP sample.
\end{abstract}

Keywords: Biofield energy treatment; $p$-Hydroxyacetophenone; X-ray diffraction; Surface area analysis; Thermogravimetric analysis; Ultraviolet-visible spectroscopy; Fourier transform infrared spectroscopy

\section{Abbreviations}

pHAP: para-Hydroxyacetophenone; XRD: X-ray diffraction; BET: Brunauer-Emmett-Teller; TGA/DTG: Thermogravimetric analysis/ Derivative thermogravimetry; FT-IR: Fourier transform infrared

\section{Introduction}

Acetophenones are the aromatic ketones that are mainly used as precursors for resins and fragrances [1]. Their occurrence was found in several natural products like apple, banana, cauliflower, etc. [2]. They were also used in medicine as hypnotics and anticonvulsants in $19^{\text {th }}-20^{\text {th }}$ centuries [3]. Hydroxyacetophenones are obtained by direct $\mathrm{C}$-acylation of phenol with acetic acid and used in manufacturing of pharmaceutical products [4]. P-Hydroxyacetophenone ( $p$ HAP) is an aromatic ketone (Figure 1) having wide commercial applications. It is also known as piceol that is a phenolic compound and can be obtained naturally from mycorrhizal roots of Norway spruces (Picea abies) $[5,6]$. It is used in the production of rubbers, plastics, agricultural chemicals, and pharmaceuticals. It acts as a precursor for the synthesis of p-hydroxyacetanilide and paracetamol (analgesic drug) [7]. It is also used as a ketone component in the manufacturing of 1-aryl-3phenethylamino-1-propanone hydrochloride that is a potent cytotoxic agent [8]. Moreover, they are also used in manufacturing of cosmetics, flavours, and fragrances [9]. Overall, the importance of $p$-HAP in industries is as the precursor and intermediate compounds. The physicochemical properties like particle size, surface area, and thermal properties of intermediate compounds play a crucial role in chemical and pharmaceutical industries $[10,11]$. Hence, authors were attempting an alternative strategy i.e., biofield energy treatment and analysed its impact on the physicochemical properties of $p$ HAP. Biofield energy treatment is a type of energy healing which comes under the branch of alternative medicine [12]. These energy therapies are also recommended by National Institute of Health $(\mathrm{NIH})$ and National Centre for Complementary and Alternative Medicine (NCCAM) [13]. Biofield is the name given to the electromagnetic field that permeates and surrounds the living organisms. It is the scientific term for the biologically produced ultra-fine electromagnetic energy field that can function for regulation and communication within the organism [14]. The features of this electromagnetic field are related to the physiological and mental state of the person and research has found that this field might deplete in unhealthy conditions [15]. Hence, the health of living organisms can be influenced by balancing this energy from the environment through natural exchange process [16]. Thus, the human has the ability to harness the energy from the environment or universe and can transmit it to any living or non-living object(s) around the Globe. The objects always receive the energy and responding to the useful way. This process is known as biofield energy treatment. Mr. Trivedi is well known to possess a unique biofield energy treatment (The Trivedi Effect") that has been reported for altering the growth and yield properties of plants in the agriculture field [17-19]. The effect of biofield treatment was also reported in biotechnology field $[20,21]$ and microbiology research [22-24]. Besides that, the impact of biofield treatment was also reported on physical, thermal and spectral properties of various metals and organic compounds [25-27]. Hence, the current study was designed to evaluate the impact of biofield energy treatment on physical, thermal and spectroscopic properties of $p \mathrm{HAP}$.

\section{Materials and Methods}

\section{Sample preparation}

$P$-Hydroxyacetophenone ( $p$ HAP) was procured from Loba Chemie

${ }^{*}$ Corresponding author: Dr. Snehasis Jana, Trivedi Science Research Laboratory Pvt Ltd., Hall-A, Chinar Mega Mall, Chinar Fortune City, Hoshangabad Rd., Bhopal-462 026, Madhya Pradesh, India, Tel: +91-755-6660006; E-mail: publication@trivedisrl.com

Received September 08, 2015; Accepted September 22, 2015; Published September 29, 2015

Citation: Trivedi MK, Branton A, Trivedi D, Nayak G, Singh R, et al. (2015) Evaluation of Physical, Thermal and Spectroscopic Properties of Biofield Treated p-Hydroxyacetophenone. Nat Prod Chem Res 3: 190. doi:10.4172/23296836.1000190

Copyright: $\odot 2015$ Trivedi MK, et al. This is an open-access article distributed under the terms of the Creative Commons Attribution License, which permits unrestricted use, distribution, and reproduction in any medium, provided the original author and source are credited. 
Pvt. Ltd., India. The sample was divided into two parts; one was kept as the control while other was coded as treated sample. The treatment sample was handed over to Mr. Trivedi in sealed pack for biofield energy treatment under standard laboratory conditions. Mr. Trivedi provided the treatment through his energy transmission process to the treated group. Both control and treated samples were characterized using XRD, surface area analyser, TGA, DSC, UV-Vis, and FT-IR spectroscopic techniques.

\section{X-ray diffraction (XRD) study}

The XRD diffractograms were recorded on Phillips, Holland PW 1710 X-ray diffractometer system. The X-ray generator was equipped with a copper anode with nickel filter operating at $35 \mathrm{kV}$ and $20 \mathrm{~mA}$. The wavelength of radiation used by the XRD system was $1.54056 \AA$. The XRD data were acquired over the $2 \theta$ range of $10^{\circ}-99.99^{\circ}$ at $0.02^{\circ}$ interval with a measurement time of 0.5 seconds per $2 \theta$ interval.

The average size of crystallite $(\mathrm{G})$ was calculated from the Scherrer equation. The method is based on the width of the diffraction patterns obtained in the X-ray reflected crystalline region [28].

$$
\mathrm{G}=\mathrm{k} \lambda /(\mathrm{b} \operatorname{Cos} \theta)
$$

Where, $\mathrm{k}$ is the equipment constant (0.94), $\lambda$ is the $\mathrm{X}$-ray wavelength $(0.154 \mathrm{~nm})$; $B$ in radians is the full-width at half of the peaks and $\theta$ the corresponding Bragg angle.

Percent change in crystallite size was calculated using the following equation:

\section{Percent change in crystallite size $=\left[\left(G_{t}-G_{c}\right) / G_{c}\right] \times 100$}

Where, $G_{c}$ and $G_{t}$ denote the crystallite size of control and treated powder samples, respectively [29].

\section{Surface area analysis}

The surface area of $p \mathrm{HAP}$ was measured by the surface area analyser, Smart SORB 90 based on Brunauer-Emmett-Teller (BET). The percent changes in surface area were calculated using following equation:

$$
\% \text { change in surface area }=\frac{\left[\mathrm{S}_{\text {Treated }}-\mathrm{S}_{\text {Control }}\right]}{\mathrm{S}_{\text {Control }}} \times 100
$$

Where, $S_{\text {Control }}$ and $S_{\text {Treated }}$ are denoting the surface area of control and treated samples respectively.

\section{Thermogravimetric analysis/Derivative thermogravimetry (TGA/DTG)}

The thermal gravimetric analysis of control and treated sample of $p \mathrm{HAP}$ was carried out using Mettler Toledo simultaneous thermogravimetric analyser (TGA/DTG). The samples were heated from room temperature to $400^{\circ} \mathrm{C}$. The heating rate was kept at $5^{\circ} \mathrm{C} /$ min under air atmosphere. From TGA curve, the onset temperature at which sample start losing weight by evaporation and from DTG curve, $\mathrm{T}_{\max }$ (temperature at which sample lost its maximum weight) were recorded.

\section{Differential scanning calorimetry (DSC) study}

Differential scanning calorimeter (DSC) of Perkin Elmer/Pyris-1 was used for studies related to melting temperature and latent heat of fusion $(\Delta \mathrm{H})$. The DSC curves were recorded under air atmosphere $(5 \mathrm{~mL} / \mathrm{min})$ and a heating rate of $10^{\circ} \mathrm{C} / \mathrm{min}$ in the temperature range of $50^{\circ} \mathrm{C}$ to $350^{\circ} \mathrm{C}$. An empty pan sealed with cover pan was used as a reference sample. From DSC curve, the melting temperature and latent heat of fusion were obtained.

The percent change in latent heat of fusion was calculated to observe the difference in thermal properties of treated $p$-hydroxyacetophenone sample as compared to control using following equations:

$\%$ change in Latent heat of fusion $=\frac{\left[\Delta \mathrm{H}_{\text {Treated }}-\Delta \mathrm{H}_{\text {Control }}\right]}{\Delta \mathrm{H}_{\text {Control }}} \times 100$

Where, $\Delta \mathrm{H}_{\text {Control }}$ and $\Delta \mathrm{H}_{\text {Treated }}$ denote the latent heat of fusion of control and treated samples, respectively.

\section{Spectroscopic studies}

The treated samples were divided into two groups i.e., T1 and T2 for determination of UV-VIS and FT-IR spectroscopic characters. Both treated groups were analysed for their spectral characteristics using UV-VIS and FT-IR spectroscopy as compared to respective control samples.

\section{UV-VIS spectroscopic analysis}

The UV-VIS spectrum of $p$ HAP was recorded in methanol solvent by Shimadzu UV-2400 PC series spectrophotometer. The spectrum was recorded over a wavelength range of 200-400 $\mathrm{nm}$ with $1 \mathrm{~cm}$ quartz cell and a slit width of $2.0 \mathrm{~nm}$. This analysis was performed to evaluate the effect of biofield treatment on the optical properties of $p H A P$ sample. The UV-VIS spectroscopy can investigates electronic transition between orbitals or bands of atoms, ions and molecules existing in the compound [30]

\section{Fourier transform-infrared (FT-IR) spectroscopic characterization}

The samples were crushed into fine powder for analysis. The powdered sample was mixed in spectroscopic grade $\mathrm{KBr}$ in an agate mortar and pressed into pellets with a hydraulic press. The FT-IR spectra were recorded on Shimadzu's Fourier transform infrared spectrometer (Japan). FT-IR spectra are generated by the absorption of electromagnetic radiation in the frequency range $4000-400 \mathrm{~cm}^{-1}$ [31].

\section{Results and Discussion}

\section{$\mathrm{X}$-ray diffraction}

$\mathrm{X}$-ray diffraction study was conducted to study the crystalline pattern of the control and treated sample of $p H A P$. Figure 2 showed the XRD diffractogram of control and treated samples of $p H A P$. The XRD diffractograms showed a series of intense peaks in the regions of $10^{\circ}<2 \theta>26^{\circ}$, which depicted that $p \mathrm{HAP}$ sample had high crystallinity and long range ordering. From the diffractograms, no broadening of peaks was evident, which showed that sample was crystalline in nature. In addition, the most intense peak was observed at $2 \theta$ equal to $15.79^{\circ}$ in control; however, it was observed at $23.22^{\circ}$ in treated sample. It

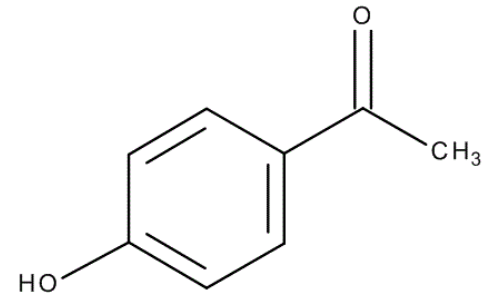

Figure 1: Chemical structure of $p$-hydroxyacetophenone. 


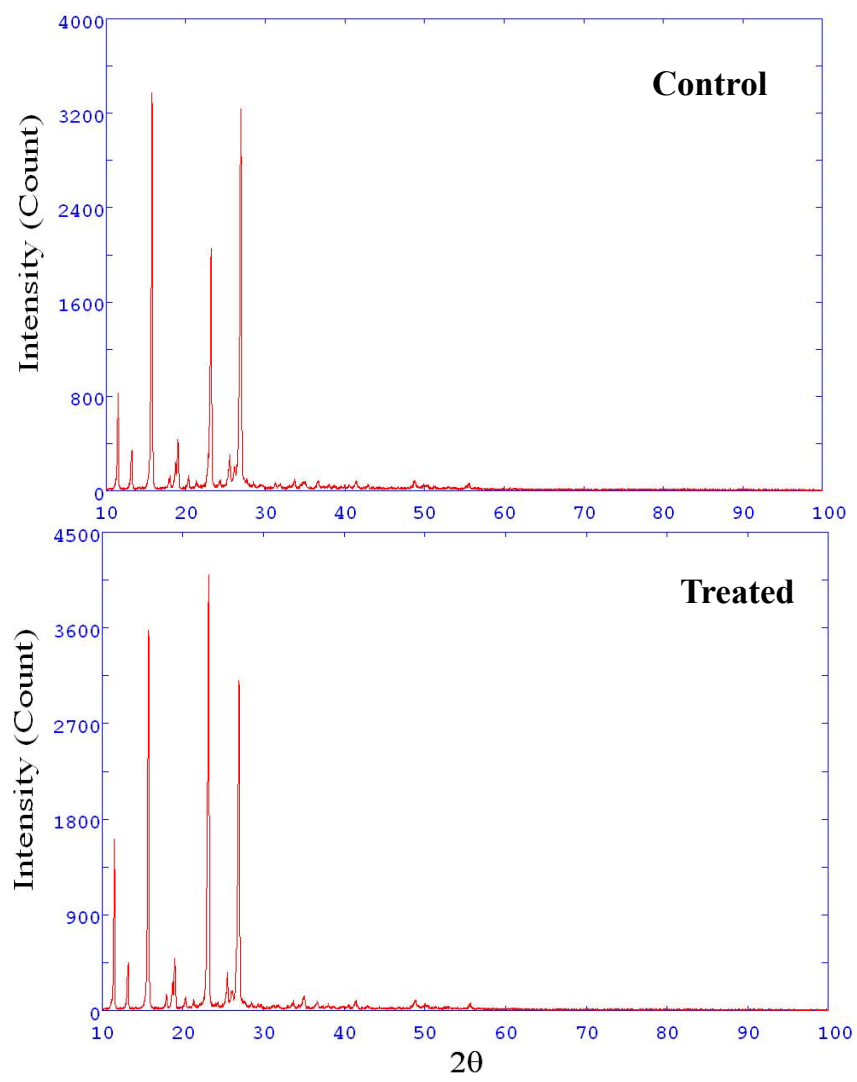

Figure 2: XRD of control and treated samples of $p$-hydroxyacetophenone

indicated that the relative intensities of XRD peaks were altered in treated $p \mathrm{HAP}$ as compared to the control sample. It is reported that the change in crystal morphology causes the alteration in relative intensities of the peaks [32]. Moreover, it was reported that $p \mathrm{HAP}$ molecules possess $\mathrm{O}-\mathrm{H}-\mathrm{O}$ hydrogen bonds due to which they exhibited a linear chain like structure. Also, these interactions were strong at lower temperature [9]. It is presumed that biofield energy may transfer energy to the treated sample that might cause breaking of these intermolecular interactions. Due to this, the $p$ HAP molecules may form a symmetrical crystalline pattern that further leads to increased symmetry of $p$ HAP molecules. Recently, our group reported that biofield energy treatment has significantly altered the particle size and surface morphology of cadmium powder [25]. Thus, it is assumed that the energy transferred through biofield treatment probably altered the shape and size of molecules of treated sample that might be the responsible for an alteration in relative intensities in treated sample as compared to the control. Moreover, the average crystallite size was calculated using Scherrer equation. The crystallite size of $p \mathrm{HAP}$ samples was found as $84.18 \mathrm{~nm}$ in the control and $61.25 \mathrm{~nm}$ in the treated sample. It indicated that the crystallite size was decreased by $27.23 \%$ in the treated $p \mathrm{HAP}$ as compared to the control. It was previously reported that ultrasonic energy can cause the decrease in crystallite size [33]. Hence, it is hypothesized that biofield energy treatment might transfer some energy that resulted in the decreased crystallite size. Besides, it was reported that decrease in crystallite size may accelerates the rate kinetics in the chemical reactions [10]. Since $p$ HAP is used as an intermediate in various chemical reactions. Hence, the decrease in crystallite size might enhance the percentage yield of end products by fastening the rate of chemical reaction.

\section{Surface area analysis}

In $p \mathrm{HAP}$, the control sample showed a surface area of $0.34 \mathrm{~m}^{2} / \mathrm{g}$; however, the treated sample showed the surface area of $0.20 \mathrm{~m}^{2} / \mathrm{g}$. The surface area of treated sample was decreased by $41.17 \%$ as compared to the control sample. Murray et al. reported that increase in crystallinity might reduce the surface area as poorly crystallized sample possess more surface area than a well-crystallized sample [34]. In addition, the alteration of crystal morphology in treated sample was evidenced from XRD data. The change in surface morphology may lead to altering the surface area. Also, another reason might be that pore volume of particles decreased significantly with increasing heat treatment that ultimately decreased the surface area of particles [35]. Hence, it was hypothesized that biofield treatment might transfer the energy that probably reduced the pore volume of the treated $p \mathrm{HAP}$ sample. It further leads to decrease the surface area of treated sample as compared to the control.

\section{TGA/DTG analysis}

The TGA/DTG thermograms of control and treated samples of pHAP are shown in Figure 3, and data are presented in Table 1. In case of control $p \mathrm{HAP}$, there was a sharp single stage of weight loss between $179^{\circ} \mathrm{C}$ and $249^{\circ} \mathrm{C}$. Since, the single stage of weight loss started at $179^{\circ} \mathrm{C}$ without any intermediate stages; it was assumed that the compound was evaporated at this temperature [36]. The sharpness of both thermograms (control and treated) also indicated that the compound was pure without the association of any impurities. However, in the treated $p \mathrm{HAP}$, there was a sharp single stage of weight loss between $192^{\circ} \mathrm{C}$ and $262^{\circ} \mathrm{C}$. It indicated that onset temperature of the treated $p \mathrm{HAP}$ was increased as compared to the control. Besides, DTG thermogram data showed that $\mathrm{T}_{\max }$ was found at $220.62^{\circ} \mathrm{C}$ in control whereas; it was increased to $232.62^{\circ} \mathrm{C}$ in the treated $p H A P$. It indicated that $\mathrm{T}_{\max }$ was also increased in treated sample as compared to the control. Furthermore, the increase in onset temperature and $\mathrm{T}_{\max }$ can be related to the increase in vaporization temperature of the treated $p$ HAP sample. Hence, it indicated that the biofield energy treatment might produce some alterations in the thermal stability profile of $p$ HAP sample. The thermal stability is critical to ensure the safe handling of chemical compounds. The thermal stability is also considered in the processing, long-term storage or shipping of material [37]. The biofield treated $p \mathrm{HAP}$ sample showed more thermal stability that might assure its safe handling and prolonged storage as compared to the control sample.

\section{DSC analysis}

The DSC was used to determine the latent heat of fusion $(\Delta \mathrm{H})$ and melting temperature in the control and treated samples of $p H A P$. The DSC analysis results (Table 1 ) showed that $\Delta \mathrm{H}$ was decreased from $124.56 \mathrm{~J} / \mathrm{g}$ (control) to $103.24 \mathrm{~J} / \mathrm{g}$ in the treated $\mathrm{pHAP}$. It indicated that $\Delta \mathrm{H}$ was decreased by $17.11 \%$ in the treated sample as compared to the control. It is possible that the treated sample might be in a high energy state due to biofield energy treatment. Also, it was observed in XRD studies that due to biofield energy, the intermolecular hydrogen bonding might be broken in the treated sample. Due to this, the treated sample might need less energy to undergo the process of melting that further may lead to the reduction in the latent heat of fusion. Moreover, in melting temperature, a slight increase was observed in the treated $p$ HAP $\left(111.81^{\circ} \mathrm{C}\right)$ as compared to the control sample $\left(109.93^{\circ} \mathrm{C}\right)$. It suggested that biofield energy treatment may induce a slight alteration in the kinetic energy of the treated sample.

\section{UV-VIS spectroscopic analysis}

The UV spectra of control and treated samples of $p \mathrm{HAP}$ are shown in Figure 4. The UV spectrum of control sample showed characteristic 

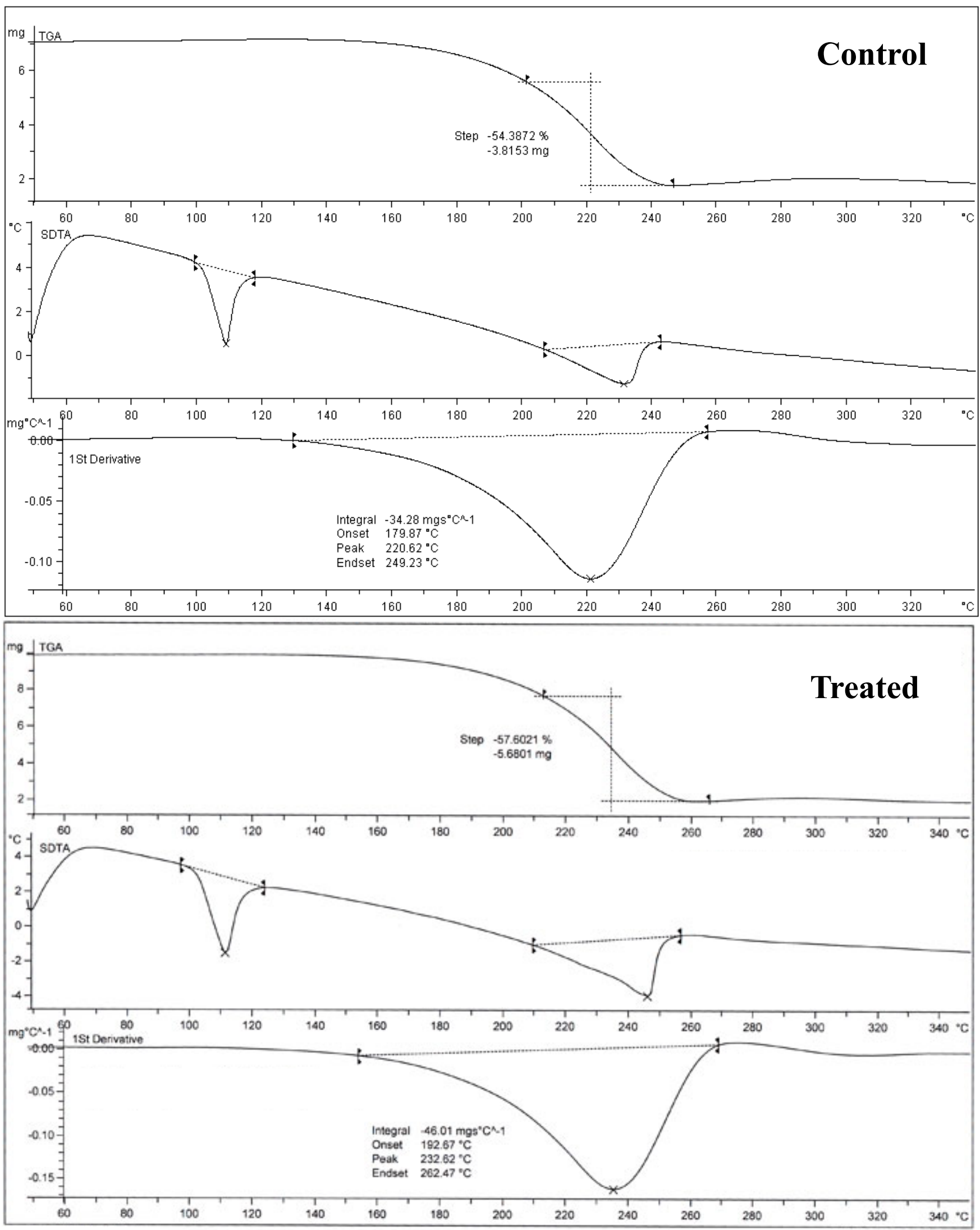

Figure 3: TGA/DTG thermogram of control and treated samples of $p$-hydroxyacetophenone. 
absorption peaks at 202, 219, and $276 \mathrm{~nm}$. The treated sample also showed absorption of light at the same wavelength. The peaks were appeared at 202, 218, and $274 \mathrm{~nm}$ in T1 while in T2 sample, at 202, 219, and $275 \mathrm{~nm}$. Moreover, the absorbance at $270-280 \mathrm{~nm}$ was assigned to $\pi \rightarrow \pi^{*}$ transition and the less intense band at 200-220 nm was may be accounted for $n \rightarrow \pi^{*}$ transition of the compound [36,38]. It suggested that biofield treatment may not cause any change in structure or position of the functional group as well as the energy that is responsible for $\pi \rightarrow \pi^{*}$ or $n \rightarrow \pi^{*}$ transitions.

\section{FT-IR analysis}

The FT-IR spectra of control and treated samples are shown in Figure 5. The spectra showed characteristic vibrational frequencies as follows:

Oxygen-hydrogen vibrations: In the present study, the $\mathrm{O}-\mathrm{H}$ stretching vibration was observed at 3311 and $3217 \mathrm{~cm}^{-1}$ in the control sample, whereas at 3308 and $3209 \mathrm{~cm}^{-1}$ in T1 and T2 samples.

Carbon- hydrogen vibrations: The peaks of aromatic $\mathrm{C}-\mathrm{H}$ stretching were observed at $2997 \mathrm{~cm}^{-1}$ in all three samples, i.e., control and $\mathrm{T} 1$, and $\mathrm{T} 2$. However, the aliphatic $\mathrm{C}-\mathrm{H}$ stretching vibration was observed at $2947 \mathrm{~cm}^{-1}$ in all three samples, i.e., control and T1, and T2. The $\mathrm{C}-\mathrm{H}$ bending vibrations were observed at 1357 and $1444 \mathrm{~cm}^{-1}$ in control and T1 sample, whereas, in T2 sample, the peaks were observed at 1357 and $1442 \mathrm{~cm}^{-1}$. The $\mathrm{C}-\mathrm{H}$ out of plane bending peak was observed at $815 \mathrm{~cm}^{-1}$ in all three samples, i.e., control and $\mathrm{T} 1$, and $\mathrm{T} 2$.

Carbon- oxygen vibrations: In the present study, the $\mathrm{C}=\mathrm{O}$ stretching vibrations was observed at $1660 \mathrm{~cm}^{-1}$ in control and T2 sample. In $\mathrm{T} 1$ sample, the $\mathrm{C}=\mathrm{O}$ stretching vibrations was observed at
$1662 \mathrm{~cm}^{-1}$. The phenolic $\mathrm{C}-\mathrm{O}$ stretching peaks were appeared as the doublet at 1278 and $1301 \mathrm{~cm}^{-1}$ in all three samples, i.e., control and T1, and $\mathrm{T} 2$.

Ring vibration: The peak due to para substituted benzene was appeared at $848 \mathrm{~cm}^{-1}$ in all three samples, i.e., control and T1, and T2. The other peaks due to ring stretching $(\mathrm{C}=\mathrm{C})$ were appeared at 1600 and $1514 \mathrm{~cm}^{-1}$ in control sample whereas, at 1600 and $1512 \mathrm{~cm}^{-1}$ in $\mathrm{T} 1$ and $\mathrm{T} 2$ samples.

A prominent peak due to $-\mathrm{C}-\mathrm{CO}-\mathrm{CH}_{3}$ bending was also observed at $1107 \mathrm{~cm}^{-1}$ in all three samples, i.e., control and T1, and T2.

The overall FT-IR analysis was supported by literature data $[39,40]$ and showed that there was no significant difference between observed frequencies of control and treated samples. Hence, it showed that biofield energy treatment might not induce any significant change at bonding level.

\section{Conclusion}

The XRD data revealed high intensity peaks in the diffractogram of treated sample that suggests that crystallinity of treated samples

\begin{tabular}{|l|c|c|}
\hline Parameter & Control & Treated \\
\hline Onset temperature $\left({ }^{\circ} \mathrm{C}\right)$ & 179.87 & 192.67 \\
\hline $\mathrm{T}_{\max }\left({ }^{\circ} \mathrm{C}\right)$ & 220.62 & 232.62 \\
\hline Latent heat of fusion $\Delta \mathrm{H}(\mathrm{J} / \mathrm{g})$ & 124.56 & 103.24 \\
\hline Melting point $\left({ }^{\circ} \mathrm{C}\right)$ & 109.93 & 111.81 \\
\hline
\end{tabular}

Table 1: Thermal analysis of control and treated samples of $p$-hydroxyacetophenone. $\mathrm{T}_{\max }$ : Temperature at which maximum weight loss occur.

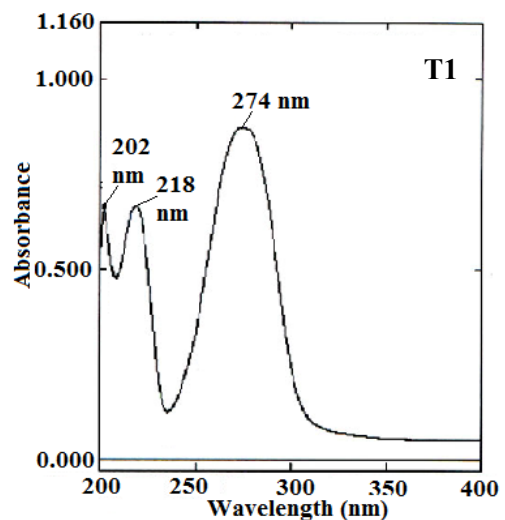

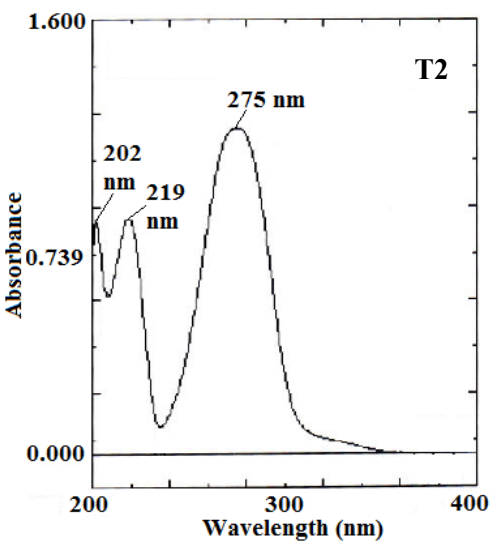

Figure 4: UV-Vis spectra of control and treated samples of $p$-hydroxyacetophenone. 
Citation: Trivedi MK, Branton A, Trivedi D, Nayak G, Singh R, et al. (2015) Evaluation of Physical, Thermal and Spectroscopic Properties of Biofield Treated $p$-Hydroxyacetophenone. Nat Prod Chem Res 3: 190. doi:10.4172/2329-6836.1000190
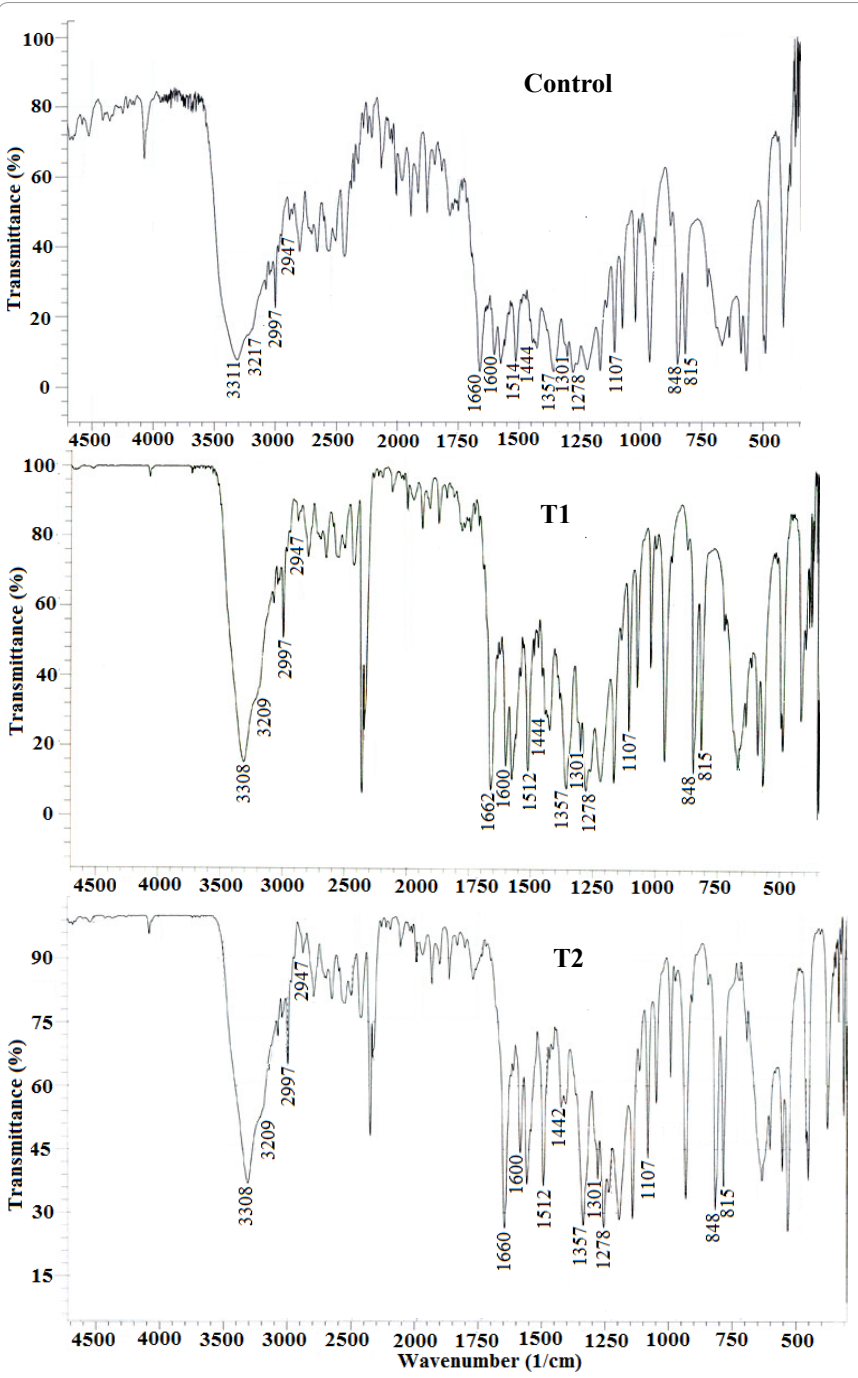

Figure 5: FT-IR spectra of control and treated samples of $p$-hydroxyacetophenone.

was increased as compared to the control sample. However, $27.23 \%$ decrease in the crystallite size was reported in the treated sample of $p$ HAP. The surface area analysis inferred that surface area of treated sample was reduced by $41.17 \%$ that might occur due to change in surface morphology of particles in treated sample as compared to the control. The TGA analysis revealed that onset temperature of decomposition and $\mathrm{T}_{\max }$ of the treated sample were increased which suggest that the vaporization temperature might enhance as compared to the control sample. Furthermore, the latent heat of fusion was decreased by $17.11 \%$ which revealed that probably the treated sample was in a high energy state due to biofield treatment and hence need less energy to undergo the process of melting. The melting temperature was also slightly increased from $109.93^{\circ} \mathrm{C}$ (control) to $111.81^{\circ} \mathrm{C}$ (treated) which suggested that biofield energy treatment might cause some alteration in kinetic energy of treated sample as compared to the control. Overall, the results showed alteration in physical and thermal properties of pHAP sample after biofield energy treatment that might assure the safe handling and stability of biofield treated compound along with improved reaction kinetics profile.

\section{Acknowledgements}

The authors would like to acknowledge the whole team from the Sophisticated Analytical Instrument Facility (SAIF), Nagpur, Indian Rubber Manufacturers
Research Association (IRMRA), Thane and MGV Pharmacy College, Nashik for providing the instrumental facility. Authors are very grateful for the support of Trivedi Science, Trivedi Master Wellness and Trivedi Testimonials in this research work

\section{References}

1. Siegel H, Eggersdorfer M (2002) Ketones. Ullmann's encyclopedia of industrial chemistry. Wiley-VCH, Wienheim.

2. Muller-Schwarze D, Houlihan PW (1991) Pheromonal activity of single castoreum constituents in beaver, Castor canadensis. J Chem Ecol 17: 715734

3. Bartholow R (2014) A practical treatise on materia medica and therapeutics. Literary Licensing LLC, USA.

4. Sobrinho EV, Cardoso D, Souza-Aguiar EF (1998) Thermodynamic analysis of phenol acylation with acetic acid. J Braz Chem Soc 9: 225-230.

5. Munzenberger B, Heilemann J, Strack D, Kottke I, Oberwinkler F (1990) Phenolics of mycorrhizas and non-mycorrhizal roots of Norway spruce. Planta 182: $142-148$

6. Acton QA (2012) Ketones: Advances in research and application. Scholarly Editions, Atlanta, USA.

7. Commarieu A, Hoelderich W, Laffitte JA, Dupont MP (2002) Fries rearrangement in methane sulfonic acid, an environmental friendly acid. $\mathrm{J}$ Mol Catal A Chem 182: $137-141$

8. Mete E, Gul HI, Kazaz C (2007) Synthesis of 1-aryl-3-phenethylamino-1propanone hydrochlorides as possible potent cytotoxic agents. Molecules 12: 2579-2588.

9. Bernardes CES, Piedade MFM, da Piedade MEM (2008) Polymorphism in 4'-hydroxyacetophenone: Structure and energetics. Cryst Growth Des 8: 24192430 .

10. Chaudhary AL, Sheppard DA, Paskevicius M, Pistidda C, Dornheim M, et al. (2015) Reaction kinetic behaviour with relation to crystallite/grain size dependency in the Mg-Si-H system. Acta Mater 95: 244-253.

11. Espenson JH (1995) Chemical kinetics and reaction mechanisms. 2nd edn, Mcgraw-Hill, USA

12. Evans J (2008) Spiritual healing on the NHS. London: The Times

13. NIH (2008) National Centre for Complementary and Alternative Medicine. CAM Basics. Publication 347.

14. Garland SN, Valentine D, Desai K, Li S, Langer C, et al. (2013) Complementary and alternative medicine use and benefit finding among cancer patients. J Altern Complement Med 19: 876-881.

15. Prakash S, Chowdhury AR, Gupta A (2015) Monitoring the human health by measuring the biofield "aura": An overview. Int J Appl Eng Res 10: 27654 27658.

16. Rubik B (2002) The biofield hypothesis: Its biophysical basis and role in medicine. J Altern Complement Med 8: 703-717.

17. Shinde V, Sances F, Patil S, Spence A (2012) Impact of biofield treatment on growth and yield of lettuce and tomato. Aust J Basic Appl Sci 6: 100-105.

18. Sances F, Flora E, Patil S, Spence A, Shinde V (2013) Impact of biofield treatment on ginseng and organic blueberry yield. Agrivita J Agric Sci 35: 22 29.

19. Lenssen AW (2013) Biofield and fungicide seed treatment influences on soybean productivity, seed quality and weed community. Agricultural Journal 8: 138-143.

20. Nayak G, Altekar N (2015) Effect of biofield treatment on plant growth and adaptation. J Environ Health Sci 1: 1-9.

21. Patil SA, Nayak GB, Barve SS, Tembe RP, Khan RR (2012) Impact of biofield treatment on growth and anatomical characteristics of Pogostemon cablin (Benth.). Biotechnology 11: 154-162.

22. Trivedi MK, Patil S, Shettigar H, Bairwa K, Jana S (2015) Phenotypic and biotypic characterization of Klebsiella oxytoca: An impact of biofield treatment J Microb Biochem Technol 7: 203-206.

23. Trivedi MK, Patil S, Shettigar H, Gangwar M, Jana S (2015) An effect of biofield treatment on Multidrug-resistant Burkholderia cepacia: A multihost pathogen. J Trop Dis 3: 167 
Citation: Trivedi MK, Branton A, Trivedi D, Nayak G, Singh R, et al. (2015) Evaluation of Physical, Thermal and Spectroscopic Properties of Biofield Treated $p$-Hydroxyacetophenone. Nat Prod Chem Res 3: 190. doi:10.4172/2329-6836.1000190

24. Trivedi MK, Patil S (2008) Impact of an external energy on Yersinia enterocolitica [ATCC-23715] in relation to antibiotic susceptibility and biochemical reactions: An experimental study. Internet J Alternat Med 6: 13.

25. Trivedi MK, Nayak G, Patil S, Tallapragada RM, Latiyal O, et al. (2015) An evaluation of biofield treatment on thermal, physical and structural properties of cadmium powder. J Thermodyn Catal 6: 147.

26. Trivedi MK, Tallapragada RM, Branton A, Trivedi D, Nayak G, et al. (2015) Potential impact of biofield treatment on atomic and physical characteristics of magnesium. Vitam Miner 3: 129.

27. Trivedi MK, Patil S, Shettigar H, Singh R, Jana S (2015) An impact of biofield treatment on spectroscopic characterization of pharmaceutical compounds. Mod Chem appl 3: 159

28. Alexander L, Klug HP (1950) Determination of crystallite size with the X-ray spectrometer. J Appl Phys 21: 137-142.

29. Thermal Degradation and Crystallisation Behaviour (2007) Part I, Polymer degradation and stability. 236-273.

30. Chabukswar V, Bhavsar S, Horne A (2011) Organic synthesis and characterization of electrically conducting poly (o-toluidine) doped with organic acid. Ch\&ChT 5: 37-40.

31. Lambert JB (1987) Introduction to organic spectroscopy. Macmillan, New York, USA.
32. Inoue M, Hirasawa I (2013) The relationship between crystal morphology and XRD peak intensity on $\mathrm{CaSO}_{4} \cdot 2 \mathrm{H}_{2} \mathrm{O}$. J Cryst Growth 380: 169-175.

33. Sumari S, Roesyadi A, Sumarno S (2013) Effects of ultrasound on the morphology, particle size, crystallinity, and crystallite size of cellulose. Sci Study Res Chem Chem Eng Biotechnol Food Ind 14: 229-239.

34. Murray HH, Lyons SC (1960) Further correlation of kaolinite crystallinity with chemical and physical properties. Clays Clay Miner 8: 11-17.

35. Behnajady MA, Aalamdari ME, Modirshahla N (2013) Investigation of the effect of heat treatment process on characteristics and photocatalytic activity of $\mathrm{TiO}_{2}$ UV100 nanoparticles. Environ Prot Eng 39: 33-46.

36. Gurnule WB, Mandavgade SK, Dontulwar JR (2012) Synthesis characterization and thermal degradation studies of polymer resin derived from 4-hydroxyacetophenone and catechol. Res J Pharm Biol Chem Sci 3: 534-544.

37. Rowe S (2007) The importance of a robust assessment procedure in protecting against rapid overpressure hazards. I Chem Eng Symp Ser No. 153.

38. Vijayan N, Babu RR, Gunasekaran M, Gopalakrishnan R, Kumaresan R, et al. (2003) Studies on the growth and characterization of $p$-hydroxyacetophenone single crystals. J Cryst Growth 249: 309-315.

39. Thakur KG, Sekar G (2011) D-Glucose as green ligand for selective coppe catalysed phenol synthesis from aryl halides with an easy catalyst removal. Chem Commun (Camb) 47: 6692-6694.

40. Bernardes CES, Ilharco LM, da Piedade MEM (2014) Polymorphism in 4-hydroxyacetophenone: A vibrational analysis. J Mol Struct 1078: 181-187. 